\title{
EDITORIAL
}

\section{Experiencia y Perspectivas del Congreso Internacional de Gerencia en América Latina}

Acabamos de realizar el I Congreso Internacional de Gerencia en América Latina, organizado por las distintas dependencias de la Facultad de Ciencias Económicas y Sociales, vinculadas directamente al campo gerencial, a saber: las Maestrías en Gerencias de Empresas y Gerencia Pública, el Centro de Estudios de la Empresa -en el cual se desarrollan diversas líneas de investigación en el campo administrativo- y la Revista Venezolana de Gerencia. El tema central del Congreso fue la realidad y necesidad de la gerencia, en el contexto actual.

A partir de los resúmenes evaluados, fueron aceptadas y discutidas un total de 138 ponencias, las cuales se clasificaron por temas afines, conformando 31 mesas de trabajo distribuidas en las tres grandes áreas en las cuales se organizó el Congreso: Gerencia Privada, Gerencia Pública y Gerencia Social y del Tercer Sector. La asistencia fue significativa, con un total de 259. Participantes. Las discusiones se realizaron a pesar del conflictivo ambiente político del país tras el golpe de estado y la exitosa restitución del hilo constitucional, gracias a la intervención masiva del pueblo bolivariano y de los sectores de las Fuerzas Armadas comprometidos con la defensa de la Democracia y de la Constitución; se demuestra así que Venezuela se crece en las dificultades. Justamente por esta circunstancia, era inevitable incluir entre los temas centrales de discusión el relativo al contexto en que se gerencia la nación: la Democracia Venezolana en la Coyuntura Actual, analizado con gran acierto y objetividad por la historiadora y politóloga Margarita López Maya; este trabajo forma parte del presente número de la RVG.

Las otras conferencias centrales del Congreso, discutieron los siguientes temas, de importancia para la construcción de la gerencia necesaria: La Lucha contra la Pobreza y el Papel de las Ciencias Gerenciales, bajo la responsabilidad de Bernardo Kliksberg; vale destacar que el Congreso también sirvió de marco a la presentación de su último libro titulado "Hacia Una Economía con Rostro Humano". El tema Gerenciando las Relaciones Industriales: Las Regulaciones de lo Nacional a lo Internacional, fue expuesto por Héctor Lucena, distinguido laboralista y ex-director de Postgrado de la FCES en la Universidad de Carabobo. La conferencia de clausura correspondió a la Directora de nuestra revista, Haydée Ochoa Henríquez, quien disertó sobre La Nueva Gestión Pública que América Latina Necesita.

El Congreso tiene deudas de gratitud con numerosas personas e instituciones, entre ellas vale destacar a las autoridades de la Fundación Banco Mara, Imelda Rincón y Gladys ViIlalobos y de la Junta Interventora del Banco de Maracaibo, Rigoberto Rincón, quienes nos 
brindaron no sólo las instalaciones de lo que fuera hace algunos años la sede de un emporio financiero centenario que sucumbió a la crisis bancaria del año 94 - hoy convertida por la fuerza de los hechos en el Palacio de Eventos del Zulia- sino también su apoyo incondicional en el proceso organizativo. Igualmente debemos reconocer el respaldo institucional de las autoridades de nuestra Facultad y muy especialmente el trabajo minucioso y sistemático realizado por el equipo responsable de la organización del Congreso, bajo la coordinación general de Mirta López Valladares y la coordinación académica de Guillermo Rodríguez.

Crear un espacio para la discusión científica de la gerencia en América Latina es una tarea apenas iniciada con este I Congreso. Hasta el presente, el debate de los temas gerenciales se ha realizado sin identidad propia, en el marco de eventos relacionados con temas generales de las ciencia sociales, excepto en el caso de la administración pública; por otra parte, las jornadas vinculadas directamente al tema gerencial, en su inmensa mayoría se aproximan más a sesiones de actualizaciones que al debate científico. Por lo tanto, tenemos por delante la tarea de darle continuidad a los Congresos de Gerencia en América Latina; en tal sentido se están manejando dos alternativas: la primera, realizar el Il Congreso de nuevo en Maracaibo el año 2004; la segunda celebrarlo en México el año 2003, organizado en forma conjunta entre la Universidad Nacional Autónoma de México y la Universidad del Zulia.

En todo caso, al margen de la decisión inmediata, lo importante es darle continuidad al debate, y contribuir de esta forma al desarrollo de la gerencia como disciplina científica. Por ello, en definitiva el Congreso deberá hacerse itinerante, recorriendo la fascinante geografía latinoamericana y facilitando la discusión en diversos contextos. Mientras se produce el próximo encuentro, la Revista Venezolana de Gerencia seguirá constituyendo para todos los estudiosos latinoamericanos, un espacio de discusión y un medio de información sobre el tema gerencial, administrativo o de gestión. La revista se posiciona cada vez con mayor solidez en la comunidad científica, como lo demuestran el riguroso cumplimiento de su periodicidad y la inclusión en nuevos índices internacionales.

Teresa Gamboa Cáceres*

* Directora del Centro de Estudios de la Empresa. 